\title{
Walk Local, Argue Local: A Campus-Based Prompt for a Basic Writing Course
}

\author{
Lance Langdon and Jens Lloyd* \\ $10 / 1 / 2020^{\dagger}$
}

\begin{abstract}
This assignment deploys place-based pedagogy in a basic writing course, and enacts it through first-person research in the form of a walking tour of a university campus. Students first read and discuss two texts about their campus: an article analyzing campus architecture and a philosophical treatise about the campus park. Students then marshal evidence gathered through a walking tour to argue with one of these texts. In addition to bolstering students' confidence for contesting claims advanced by authorities, this assignment encourages students and teachers alike to cultivate a more deliberate awareness of their surroundings. Because this assignment is meant to be grounded in a specific locale, instructors adapting this prompt are encouraged to seek out texts addressing their own institutional settings.
\end{abstract}

Aldrich Park, a circular greenspace at the heart of the University of California, Irvine (UCI) campus, is riddled with desire lines. Crisscrossing the preordained geometry of the walkways delineated by campus planners, these desire lines indicate paths that campus inhabitants have made for themselves. Some track through the center of the park, while others skirt the edges. Some are well trod and well defined, while others are nascent and barely discernible. All mark attempts by inhabitants to push back against the design of Aldrich Park, to push back against the planners who composed the space. In this way, these desire lines are manifestations of individuals grappling with and responding to authority.

This process of grappling with and responding to authority is one that students face regularly in our writing classrooms. We tell students we want their opinions and value their perspectives on a topic, and, to stimulate their thinking and provoke discussion, we furnish them the best that professional writers and academics have written on the subject.

\footnotetext{
${ }^{*}$ Rosary Academy, langdonlance@gmail.com; Drew University, jlloyd@drew.edu. Copyright 2020 Lance Langdon and Jens Lloyd. This work is licensed under a Creative Commons Attribution-NonCommercial 4.0 International License (http://creativecommons.org/licenses/by-nc/4.0/).

${ }^{\dagger}$ Submitted, 7/8/2019; Accepted, 4/9/2020.
} 
But, just like inhabitants facing the preordained geometry of a campus park, students can be reluctant to step off the demarcated paths. They can be reluctant to challenge the authority of assigned texts, an authority endorsed not just by the publishers who have deemed these texts worthy of circulating but by us, the instructors, who lend these ideas our silent endorsement just by distributing them to students. Moreover, students can be chastened by the intellect displayed in the readings, not to mention the stylishness of the prose, and this is often especially true for students in basic writing courses.

How is a student to summon the confidence to develop their own ideas in this situation, not to mention gather the evidence needed to present those ideas persuasively? How is a student to summon the confidence to forge their own desire line? In this article, offering place-based, first-person investigation as a method for helping basic writers chart their own desire lines in academic discourse, we share a prompt that asks students to use their experiences of the campus to engage with assigned texts that advance arguments about the campus.

In inviting writing instructors to locate their pedagogy in meaningful ways on the campuses they and their students inhabit, we find common cause with place-based pedagogy, which emerges from the conviction, articulated best by David A. Gruenewald (2014), that "[p]laces, and our relationships to them, are worthy of our attention because places are powerfully pedagogical" (p. 143). Though the pedagogy originated in K-12 contexts, the last two decades have witnessed what Nedra Reynolds (2007) deems "a decided shift towards place-based pedagogies" in rhetoric/composition, as trends such as service learning and ecocomposition have inspired teachers to "connect writing students with their environments" (p. 260). Place-based assignments bring into focus and make a part of the pedagogical endeavor a variety of human and non-human elements. Such assignments, according to Nathan Shepley (2014), are most effective when they "help student writers integrate their ideas more fully into the constructed, multifaceted environments around them" (Deciding What to Value section, para. 6). Though these assignments often prompt students to "connect" with places beyond the campus, there is a subset that encourages students to "integrate their ideas [and, by extension, themselves] more fully into the constructed, multifaceted" geography of the campus. Our desire to name and define campus-based pedagogy as a subset of place-based pedagogy is not meant to affirm the flawed notion that campuses are set apart from the rest of the world. We acknowledge that campuses are vitally enmeshed with their local and regional environs. Yet we maintain that campuses are also distinct social and material sites that deserve a dedicated set of pedagogical practices.

Campuses vary in shape, size, purpose, and population; therefore, campus-based pedagogy is marked by heterogeneity. Nonetheless, in surveying some of the literature (Blakely \& Pagnac, 2012; Feinberg, 2004; Hunter, 2011; Krug, 2015), we note that these pedagogical endeavors are united by an interest in encouraging students to perceive the institutional terrain as the grounds for robust intellectual and rhetorical engagement. For new students 
in particular, a campus-based curriculum can correspond to the process of deliberately inhabiting or becoming familiar with new surroundings. We see this on display most especially in the introductory course sequence at Iowa State University (ISU) outlined by Barbara J. Blakely and Susan B. Pagnac (2012) that "operationalizes campus place not as a generic, neutral backdrop that students pass through on their way to a vocation, but as a purposeful and rich assemblage of physical, verbal, and natural artifacts that play an important role in students' adjustment process and in their higher education journey" (p. 13). In one of their major assignments that analyzes the built environment, Blakely and Pagnac note how the assignment moves beyond "description and personal reaction" to include "analytical elements addressing why a building or a piece of art is appropriate and meaningful for [ISU], how it fits into this place's history and contributes to the institution's educational mission, and how it signifies, however subtly and aesthetically, the educational opportunities the campus place offers for students" (p. 28). Ultimately, Blakely and Pagnac's course sequence requires students to become familiar enough with the campus to craft persuasive claims about it.

Beyond helping students acclimate to new surroundings, other assignments that we classify as campus-based pedagogy invite students to critique their campuses by adopting specific methodologies and critical lenses. Explaining her efforts connected with the Ethnography of the University Initiative (EUI), Gina Hunter (2011) underscores the radical potential of student-generated critique. "Ethnographic inquiry," she argues, "is one way to harness students' unique knowledge of and special position within the university while, at the same time, helping them question the often taken-for-granted aspects of their university experience" (p. 20). Matthew I. Feinberg (2004) turns to critical geography for help in designing a writing assignment that has students analyzing the implicit ideologies that constitute their educational environment. Rather than directing scrutiny beyond the boundaries of the campus, which risks defining academic work broadly and college writing specifically as the products of "disinterested observers" (p. 58), Feinberg hopes that this assignment "rais[es] students' awareness of their relationship with the spaces they inhabit and the ideological components of these settings" (p. 59). Generating awareness takes a less individualized form in an assignment detailed by Aubrey Streit Krug (2015) that has students contemplating the campus through an environmentalist lens. Describing a first-year composition course she taught at the University of Nebraska in Lincoln, Krug introduces a "perennial pedagogy" that aims to counteract students' transitory experience of the campus by getting them to cultivate "an active and reflective sense of place" (p. 111). For one assignment, using as a model text James J. Farrell's The Nature of College, Krug asks students "to identify an issue question about our local educational place" and then to compose "an exploratory argument considering ways different stakeholders might answer that question before coming to their own conclusions" (p. 117).

Our assignment encourages both the habitation and critique called for in these aforementioned examples of campus-based pedagogy. Specifically, like Krug's assignment, our 
prompt asks students to build on and/or contest already-existing arguments about the UCI campus - a large, public, research-intensive university in the southwestern United States. Students write an argumentative essay responding to a published article about UCI. Writers have two options: respond to William Cronon (1996), a philosopher who ruminates on the artificiality of Aldrich Park, or respond to Alan Hess (2014), an architectural critic who takes readers on a tour of campus buildings. This prompt was assigned by Lance in a basic writing course that primarily served two groups: 1) international students transitioning out of an English-learner program and into the first-year writing program, and 2) domestic, multilingual, first-generation college-goers from working-class families. Campus-based pedagogy, we believe, is especially advantageous for these and other cohorts of basic writers who, as a result of their placement in developmental courses, may feel initially out of place or excluded on campus.

\section{Designing the Assignment, Observing the Outcomes}

The assignment emerged from our discussions about how to make the most of the campus environment we share with students. At the time, Jens was completing a dissertation that applied the insights of rhetoric/composition's spatial turn to campus life, and Lance was looking for ways to reinvigorate his composition courses. When asked by Lance about campus-specific readings, Jens recommended the pieces by Cronon and Hess. Lance incorporated the walking tour component to enact experiential learning as a stimulus to thinking (Dewey, 1933). The tour shares features with other activities like writing marathons (Martens, 2015) that encourage groups to participate in a common experience and process that experience together through composing and sharing writing. Such activities aim to increase students' interest in the readings by revealing the materiality of the subject matter. Not merely confined to the pages of the assigned readings, the park and campus architecture became interactive elements which students could view from different perspectives and at different times, and within which students could share insights conversationally during the tour.

Transforming aspects of the readings into interactive elements was a key component of Lance's design for this assignment, as he had long noted that many first-year students defer to the authority of assigned texts when forming arguments and struggle to find evidence with which to challenge the claims being made in those texts. Lance hoped that students' sustained, direct observations of the places mentioned by Cronon and Hess would encourage students to consider themselves as authorities on those spaces, and that this would in turn help them to form and defend their own arguments about the campus.

The first step for students was to understand the arguments advanced by Cronon and Hess. Accordingly, Lance led class discussions on both readings. Cronon, a professional philosopher, writes not so much for first-year college students as for his philosophical 
peers, troubling the distinctions they make between artifice and nature, humanity and the environment. Hess, an architect, is more interested in reaching a lay audience. For example, Hess corrects the common misconception that the buildings making up UCI's historic core are "brutalist" by noting the finer touches of their design. Though Cronon was more difficult, both articles required unpacking. Accordingly, in addition to talking through study questions on the readings, Lance led students in a sentence-by-sentence reading of the heart of Cronon's argument to help them trace the logic of its development, and he provided them with visual examples that helped them to grasp the differences in architectural movements referenced by Hess. The class also read excerpts from Graff and Birkenstein's They Say/I Say to learn frameworks that gave them options for phrasing their responses to Hess's and Cronon's arguments.

Then came time for the campus tour. Lance met students outside the classroom and distributed a multi-page handout. Passages from the two readings appeared on the left of the page, in the order the walking tour would follow (first the building where class was held, then the adjacent library, etc.). Blank space was left on the right for notes students would take as Lance led the tour, pointing out the locations mentioned in the readings and encouraging students to reread the passages as they observed the places firsthand. Lance was fortunate in that the professional authors described adjacent spaces: Hess described buildings making up the historic campus core, and these buildings encircled Aldrich Park, the subject of Cronon's treatise. Lance varied instruction on the architectural portion of the tour, sometimes letting students read and observe quietly, and other times asking students to voice their own perspectives to the whole class or in pairs. The tour concluded in the park, where students sat and reread the Cronon's thoughts, explored the grounds that he deemed artificial and unnatural, and again compared Cronon's observations and conclusions with their own.

The assignment was, for most students, a success. When discussing campus architecture, the most ambitious students conducted independent research, with some even visiting on-campus archives to seek out old photos and original design documents for campus buildings. In response to Hess's metaphorical descriptions, students constructed their own metaphors to characterize campus buildings in support of their interpretations (e.g. a "mushroom-shaped" building for an organic style). When observing nature in Aldrich Park, many made close observations of local flora, turning a microscope, as it were, to patterns in bark, or in the trunks and branches of the trees. Taking up and taking on Cronon's ideas, students decided for themselves whether it mattered that many of the plants in the park were non-native and whether sandblasting out an underground rock formation for surface display rendered it unnatural.

Lance had not anticipated how much students' disciplinary backgrounds would shape their observations and arguments. Responding to Cronon, one biology major discussed the diachronic growth and development of the local flora in the campus park, which in her 
view had allowed the space to develop into an established, self-sustaining ecosystem by the time she arrived on campus, though it hadn't yet been when Cronon visited the park in its earlier days. Several other students wrote euphonious descriptions of Aldrich Park's natural beauty, presumably following on pastoral writing traditions. Responding to Hess, many writers addressed buildings in which they spent a good deal of time, often because of their majors (e.g. the engineering building), and they commented with insight as to how the form of the buildings impacted their functionality - from the placement of restrooms to the certain slant of light found in the study carrels on spring afternoons.

Yet even as students brought their individual expertise to what they observed, it mattered that they began this writing together on the tour. While they each had their own copies of the readings and their own blank halves of pages to fill, students revisited these readings and made their observations seated amongst peers in a different configuration than what the usual classroom afforded. As students ventured contrary opinions or unexpected analogies, this configuration seemed to more readily enable productive side-conversations to pop up and flourish. It might also be that there was something liberating to thought in being not just on campus, but outdoors. Lance and his students were away from rigid lines of creaking desks and subject to the traffic of other campus dwellers - insects, professors, picnickers, custodians. As students sat, observed, and wrote, they were lit by the same sun that threw the forms of campus architecture into relief, buffeted by the same wind and moisture that fed the plants in the park.

\section{Acknowledging Limits, Pondering Possibilities}

Though the assignment achieved much of what it was designed to do in Lance's basic writing course, it could be extended in a number of different directions, especially if translated to intermediate or advanced writing courses. Students could respond to multiple sources rather than just one, juggling and synthesizing a number of viewpoints about their campus. More ambitiously, the class could generate their own texts about campus spaces by soliciting the perspectives of campus staff. In a previous version of this course, custodial workers on campus had graciously taken the time to be interviewed by Lance's students, a project inspired by Proyecto Carrito (Marko, Osorio, Sepenoski, \& Catalani, 2015). One could do the same here, asking staff to document how they use the space, and thereby bringing to light arguments about the campus that may be ignored by, or invisible to, students and faculty. The dialogues program at the University of Colorado, Boulder (2019) has modeled how such conversations can be facilitated, and Paula Mathieu (2005) suggests procedures for honoring and reimbursing the time that community members commit to such conversations.

We also recognize that this assignment might seem to exclude those with different mobilities or health concerns. Appreciating this fact, we think it is essential to account for such differences by, for instance, ensuring the accessibility of all stops on the tour or spending 
considerable time at a single accessible spot. Most pointedly, we think that, in the interest of avoiding exclusionary language, future iterations of the assignment would benefit from using the term "wandering" instead of "walking." One upside of the term is how similar it is to wondering, which is precisely what we hope students do as they traverse the campus terrain.

\section{Different Places, Different Prompts}

While we have focused mostly on the impact on students, we believe that it is just as important to document the impact that assignments like this can have on instructors. Especially in a profession defined by rootlessness, campus-based assignments offer a viable means for teachers to learn about the institutional geographies they, at times tenuously, inhabit.

As a result of this assignment, long after the term ended, Lance retained a deepened appreciation for student life on the UCI campus - for what places students inhabited when not in class, and for how they made use of campus resources in parks and quads, restrooms and libraries. Lance also came to inhabit the campus more deliberately, and to make use of it in his teaching. For example, Lance has since held class meetings in a space in Aldrich Park, which students noted as welcoming. And though Lance's background is in the humanities, he took to working in the science library, whose virtues of space and light were highlighted in multiple student papers. Lance suspects that students, too, might more deliberately inhabit the spaces they discovered and discussed on the tour and in their writing. In a different fashion, Jens has experienced the benefits of campus-based pedagogy after accepting a position that required a coast-to-coast relocation. In his first term of teaching at his new institution, Jens deployed campus-based assignments in an introductory writing course for ELL students. Some students had more experience with the campus than Jens did. Though initially thrown off by feeling that he was not knowledgeable enough about the new terrain to incorporate it into the course, Jens found that there was an added measure of authenticity to the way he both framed the assignments for students and responded to their rough drafts. That is, there was a renewed exigence for Jens to draw pedagogical inspiration from his surroundings.

Importantly, the assignment we present here is not the assignment of everywhere. An assignment like this requires local, grounded texts that invite responses from students. In this way, such an assignment poses challenges to instructors precisely because it is fueled by the particularities of place. This caveat, which ought to accompany any call for place-based pedagogy, is expressed eloquently by Douglass Reichert Powell (2012) in his work on developing teaching practices that incorporate critical regionalism: "It would be paradoxical, at least, to offer a prepackaged set of tips or tricks [...], since the details of any such project must be determined in a generative relationship to the local landscape and the 
particular admixture of broader forces that converge there" (p. 191). Following Powell, we believe that this particularity is not a weakness but a strength of the specific assignment we offer and of campus-based pedagogy more broadly.

We want to leave readers interested in adapting this assignment to their own institutional geographies with two important principles. First, discern the features of your campus that make it distinctive. For instance, at UCI, the campus park and the architectural style of the original buildings distinguish it from other campuses. Students encounter these features often, but are rarely asked to think about them, read about them, or write about them. What features of your campus do you want to make a part of the pedagogical endeavor? Second, find sources that are relevant to your campus and then build your assignments around these sources. Recognizing that both Cronon and Hess advanced original arguments about the campus, Lance realized he could have students rely on their own authority as campus inhabitants to oppose or complicate the arguments advanced in the assigned readings. Relatedly, we would strongly encourage instructors to scour campus newspapers and other campus publications for possible readings. Any piece of writing that makes a claim about the campus can be rich material for walking (or wandering) local and arguing local.

\section{Assignment: Arguing Architecture, Arguing Nature}

See the Supplementary Files for this article at thepromptjournal.com for a PDF facsimile of the original formatting of this assignment.

1000-word Argumentative Essay

You must present your opinion about a space on our campus, and in so doing, respond to someone else's opinion about that space. You have two choices:

- Nature Option: Make observations about nature here on campus that respond to Cronon. What does Cronon say nature is? What, in your opinion, is nature? And how does Aldrich Park--or some other "natural" space on campus--fit or not fit that definition? For this option, remember that when writing philosophical essays, it is important to define your terms (e.g. nature). It sometimes helps to define your term by opposing it to another common term or to a term or terms you make up (i.e. artificial, art, naturey, etc.).

- Architecture Option: Make observations about campus architecture that respond to Hess. Pick a building or two you know well and answer the questions below in the order you see fit. In YOUR opinion, is the campus architecture beautiful, or brutal, or something else? (Bonus if you say it is not beautiful or beautiful, but something else, 
and if you can define what that something else is and give evidence of it.) Consider the features noted by Hess, including passive solar "fins," raised terraces, raw concrete, and so on. Whatever building you focus on, it will help to view the building from different perspectives (i.e. from out front, below, inside on the 5 th floor, the roof, etc.) and at different times of day (during passing period, at night, etc.).

Whether you respond to Hess or Cronon, when you summarize the author's perspective, be sure to include at least two different comments from that author (via paraphrase and/or quotation). Also, as you present your perspective, use transitional words to make it clear whether you are adding to, contradicting, or agreeing with the source's opinion.

Your purpose for this writing assignment is primarily to convince. Your firsthand observations will support your opinion. Thus, you should use specific nouns, action verbs, and colorful adjectives as you describe the place. These will enable your readers to picture the place in their minds after reading your commentary. You'll definitely need to use disciplinespecific vocabulary, whether from architects and architectural critics or philosophers and naturalists.

Finally, to support your opinion, you might also dig up other observations about our campus from the following sources: [Campus-specific list].

In preparation for peer review, please provide brief directions in your writing for how a peer can find this place in order to observe it.

"You Say, I Say" Peer Response (250 words)

Visit the place described by your peer and respond to their observations. Find in their writing at least one comment that you can agree with, and one comment that you're able to contradict or add to. Be sure to respond to both by providing your own evidence (i.e. observations).

\section{References}

Blakely, B. J., \& Pagnac, S. B. (2012). Pausing in the whirlwind: A campus place-based curriculum in a multimodal foundation communication course. Journal of Writing Program Administration, 35(2), 11-37.

Cronon, W. (1996). In search of nature. In Uncommon ground: Rethinking the human place in nature (pp. 23-68). WW Norton \& Company.

Dewey, J. (1933). How we think, a restatement of the relation of reflective thinking to the 
educative process. D. C. Heath and Company.

Feinberg, M. I. (2004). Critical geography and the real world in first-year writing classrooms. The Journal of the Assembly for Expanded Perspectives on Learning, 10(1), 52-61.

Gruenewald, D. A. (2014). Place-based education: Grounding culturally responsive teaching in geographical diversity. In D. A. Gruenewald \& G. A. Smith (Eds.), Place-based education in the global age (pp. 161-178). Lawrence Erlbaum Associates.

Hess, A. (2014). Erasing Pereira. Orange Coast Magazine. Retrieved from https:// www.orangecoast.com/features/erasing-pereira/

Hunter, G. (2011). Students study up the university: Perspectives gained in student research on the university as institution. Pedagogy: Critical Approaches to Teaching Literature, Language, Composition, and Culture, 12(1), 19-43.

Krug, A. (2015). Solving for perennial patterns in university composition: Connecting local and global arguments for place-conscious citizenship. In R. Brooke (Ed.), Writing suburban citizenship: Place-conscious education and the conundrum of suburbia (pp. 109-132). Syracuse University Press.

Marko, T., Osorio, M. E., Sepenoski, E., \& Catalani, R. (2015). Proyecto Carrito - When the student receives an 'A' and the worker gets fired: Disrupting the unequal political economy of translingual rhetorical mobility. Literacy in Composition Studies, 3(1), 21-43. http://doi.org/10.21623/1.3.1.3

Martens, S. (2015). Move the writer, move the pen, move the mind, change the world: Writing marathons for place-conscious teaching in suburbia. In R. Brooke (Ed.), Writing suburban citizenship: Place-conscious education and the conundrum of suburbia (pp. 42-69). Syracuse University Press.

Mathieu, P. (2005). Tactics of hope: The public turn in English composition. Boynton/Cook Publishers.

Powell, D. R. (2012). Critical regionalism: Connecting politics and culture in the American landscape. University of North Carolina Press.

Reynolds, N. (2007). Cultural geography and images of place. In C. Keller \& C. Weisser (Eds.), The locations of composition (pp. 251-266). State University of New York Press.

Shepley, N. (2014). Environmental flux and locally focused college writing. Composition Forum, 29. Retrieved from http://compositionforum.com/issue/29/environmental-flux.php

University of Colorado, Boulder. (2019). CU Dialogues Program. Retrieved from https: //www.colorado.edu/cudialogues/ 